RESEARCH ARTICLE

\title{
Osteological variation of the olive barb Puntius sarana (Cyprinidae) in Sri Lanka
}

\author{
F. I. Irfan and K. B. Suneetha Gunawickrama* \\ Department of Zoology, Faculty of Science, University of Ruhuna, Matara.
}

\begin{abstract}
Osteological intra-specific variation was studied in olive barb Puntius sarana Hamilton 1822, from six water bodies in Sri Lanka. Discernible variation was reported in the elements of the cranium, pharyngeal bones and caudal skeleton of the fish. The curvature of the median suture between frontals of the skull roof in fish from the rivers Walawe, Nilwala and the Kirindi Oya was directed opposite to that in fish from the rivers Menik, Gin and Kalu. Shape of the tip of dorsal limb of the pharyngeal bones was either most commonly pointed or truncated. Consistent distinctiveness in the rudimentary neural arch of the compound centrum was observed in the Walawe River population, while double neural spines were present on preural centra (PU2 or PU3) of the caudal skeleton in some populations. The size of the parhypural foramen and epural distance in the caudal skeleton, and the total number of vertebrae of the axial skeleton also showed variation. The results are the first information on osteological variation of P. sarana in Sri Lanka.
\end{abstract}

Keywords: Geographic variation, olive barb, osteological comparison, Puntius sarana taxonomy.

\section{INTRODUCTION}

Puntius sarana Hamilton 1822 is a cyprinid fish widely distributed across the southern part of Peninsular India and in Sri Lanka (Jayaram, 1991, 1999; Talwar \& Jhingran, 1991) and is the largest species of the genus in Sri Lanka (Pethiyagoda, 1991). External appearance is unequivocal with olive coloured dorsal side, silvery lateral sides with golden reflection and a conspicuous black blotch on the caudal peduncle (Deraniyagala, 1952) (Figure 1A). Juveniles are reported to have an additional black spot on the body just below the dorsal fin, and fins vary in colour ranging from dusky brown to orange (Deraniyagala, 1952). Valued as an edible fish in Sri Lanka, its distribution ranges from lowland waters up to an elevation of about $500 \mathrm{~m}$, particularly in clear, slow flowing rivers, streams and lakes with sandy, pebble and occasionally muddy bottoms (Pethiyagoda, 1991). It can tolerate brackish water conditions and strong currents (Kortmulder et al., 1990).

Studies on intra-specific variation are important in problems of species delineation, as it is acknowledged that inadequate information on intra-specific geographic variation can lead to erroneous species descriptions (Ishihara, 1987). Among other phenotypic tools, osteological characters are considered to be important diagnostic traits for interpreting systematics and phylogenetic relationships within Teleostei (Nybelin,
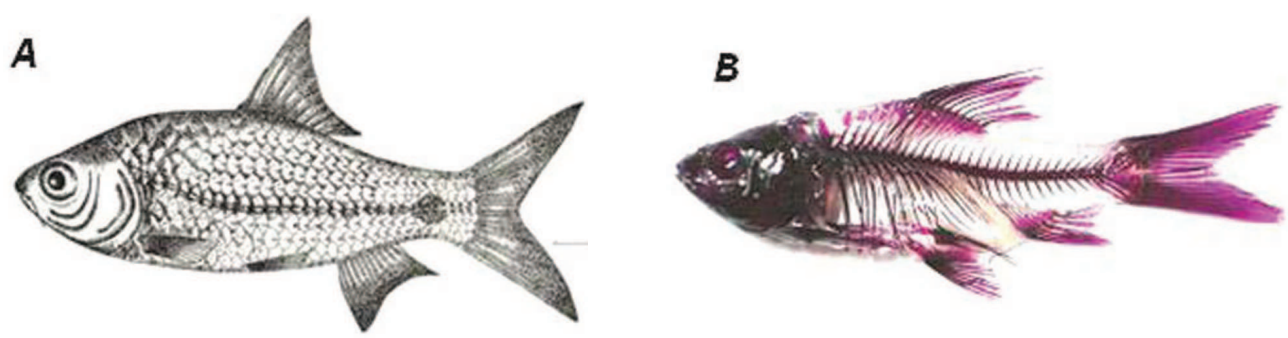

Figure 1: P. sarana (A) Illustration of a specimen collected from Walawe River (scale bar $=1 \mathrm{~cm})$, and $(\mathrm{B})$ an osteological preparation (52.4 mm SL; from Nilwala River at Godapitiya)

* Corresponding author (suneetha@zoo.ruh.ac.lk) 
1973; Arratia, 1983, 1997, 1999; Schultze \& Arratia, 1988). Dunn $(1983,1984)$ reviewed the use of skeletal structures and the utility of developmental osteology in taxonomic studies. Osteological characters may also provide a major tool in examining variability within a species (Eastman, 1980) since different populations of the same species, which share external appearance, may vary in skeletal structures (Hilton \& Bemis, 1999). Some studies (Weisel, 1960; Eastman, 1980; Arratia, 1983; Sanger \& McCune, 2002) have reported intra-specific variation in caudal and cranial osteology of fishes. Intraspecific variation in $P$. sarana in Sri Lanka has not been extensively reported yet, and therefore, taxonomically important diagnostic variation in the species is poorly understood. A recent study by Shantakumar \& Vishwanath (2006) has reported some osteological information of $P$. sarana group in India, but such studies on $P$. sarana in Sri Lanka are not available. The present study aimed to reveal osteological variation in P. sarana among selected geographic populations in Sri Lanka. Information on osteology of $P$. sarana in Sri Lanka would facilitate comparative studies with data from other locations of the distribution range within Asia, and thereby contribute to the taxonomic clarification of the species in Sri Lanka.

\section{METHODS AND MATERIALS}

Sample collection: Samples of P. sarana were collected from six freshwater bodies, namely, the Menik River

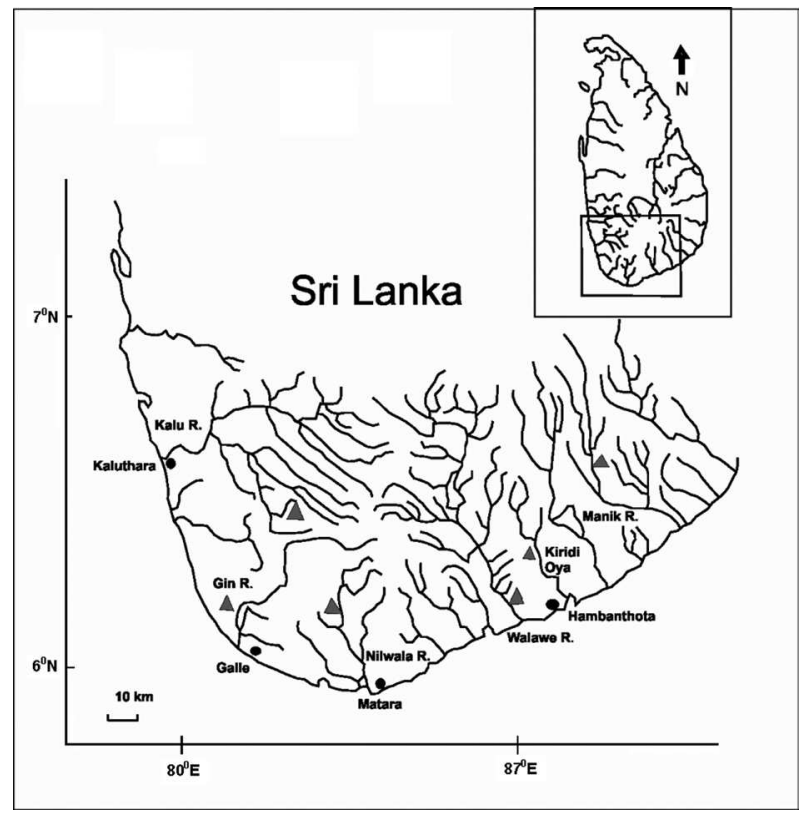

Figure 2: Collection localities (triangles) of $P$. sarana (Codes for rivers; 1: Kalu River, 2: Gin River, 3: Nilwala River, 4: Walawe River, 5: Kirindi Oya, 6: Menik River)
(M) at Kataragama, the Kirindi Oya (K) at Tissa, the Nilwala River $(\mathrm{N})$ at Godapitiya, the Gin River $(\mathrm{G})$ at Wakwella, the Kalu River (KR) at Athwelthota, and the Walawe River (W) at Pattiyapola (tank hydrologically connected) in Southern and Western Provinces of Sri Lanka (Figure 2). Sample collection was carried out from January to December 2008. A total of $3-6$ specimens of sub-adults from each location (standard length range $46.4-69.5 \mathrm{~mm}$ ) were used for osteological preparations. Fish were collected from multi-meshed gill nets and gape nets, or collected from catches of fishermen. Fish were identified using taxonomic descriptions given in Munro (1955).

Osteological analysis: Osteological preparation of the whole fish specimens (Figure 1B) (initially stored in $5 \%$ formalin and subsequently fixed in 70\% alcohol) followed the method described by Taylor \& Vandyke (1985) using Alizarin Red-S. Line drawings of the separated bones of 3-6 specimens from each location were made using a Camera Lucida fixed to a Wild M5A stereomicroscope. The nomenclature of the caudal and cranial elements follows published osteological work (Weisel, 1960; Arratia, 1983; Sanger \& McCune, 2002). In addition, the distance between the distal end of the rudimentary neural arch of compound centrum and the proximal end of the epural is referred to as epural distance.

\section{RESULTS}

Cranial portion of $P$. sarana skull-roof was more or less asymmetrical in the dorsal view (Figure 3). Dorso-median cranial fontanel is absent in all studied specimens, and the adjacent bones are abutted firmly. The bony elements of the neurocranium from the dorsal view are the frontals, parietals, pterotic, and supraoccipital. Frontals, the largest of the skull bones covering a considerable part of the skull on the dorsal side, are flat and elongated anteriorly while broad and thick posteriorly. The frontal bones are single ossified plates, which overlap medially and their dorsal view in some skulls reveal an underlying ridge, which gives a virtual appearance of each frontal being divided into two parts. The paired parietals are small and relatively thin bones situated in between frontals and supraoccipital in the hindmost region of the skull. They are attached to the supraorbital margin of the frontal bone antero-laterally, and to the pterotic laterally. The pterotics occupy the postero-lateral corners of the skull and are conspicuously irregular in shape.

Although the composition of cranial bones did not show any variation, the shapes and the arrangement 


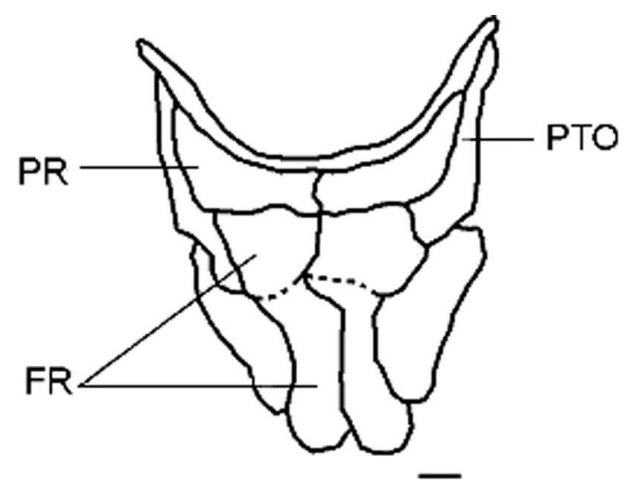

Figure 3: The cranial skeleton of $P$. sarana, $53.8 \mathrm{~mm}$ SL. (FR- frontal bones; PR- parietal bone; PTO- pterotic bone; scale bar $=1 \mathrm{~mm})$.

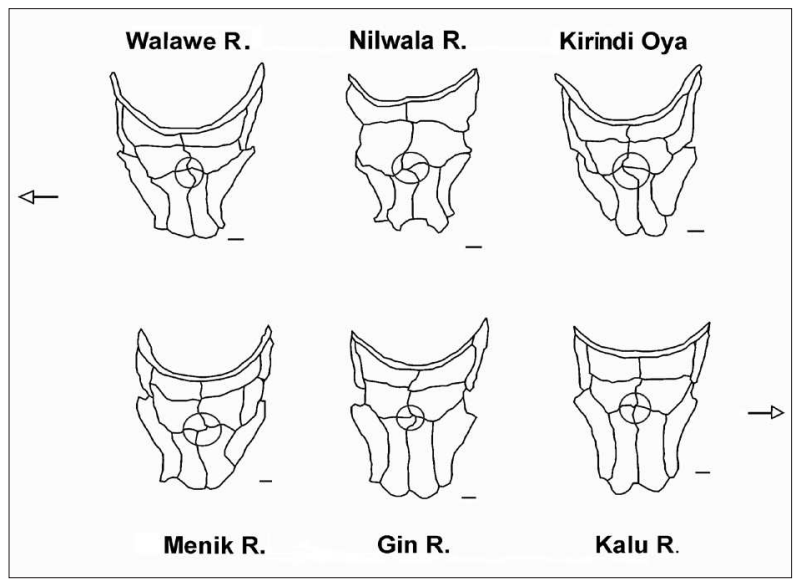

Figure 4: Variation in the cranial skeleton of $P$. sarana from six locations (the arrows indicate the curvature direction along mid cranial region for each row; scale bar $=1 \mathrm{~mm}$ ). of cranial bones, particularly the direction/ path of suture between left and right halves of the cranium, showed variation among studied specimens of $P$. sarana (Figure 4). The specimens of the rivers Menik (M), Gin (G), and Kalu (KR) had oppositely directed curvature at the suture between left and right frontals compared to the specimens from the rivers Walawe (W), Nilwala (N), and the Kirindi Oya $(\mathrm{K})$.

Pharyngeal bones of $P$. sarana are relatively broad and stout (Figure 5). The tip of the dorsal limb (dorsal lip) is usually pointed, and the upper angle along the outer edge is unrecognizable. Congregated teeth on the pharyngeal bones are moderate in size and arranged in three rows. The common dental formula on the two bones is 2, 3, $5-5,3,2$, where the outermost or the first row has two slender teeth. The thickness and the size of the teeth increase inwards, thus the last or the inner main row has five conspicuously larger broad teeth. However, two populations (the Walawe and the Menik rivers) had slightly different shapes of pharyngeal bones, where its dorsal lip is truncated and can be clearly distinguished from those in other specimens (Figure 5). Dental formula was not different among the populations.

The vertebral column of $P$. sarana generally consists of 36 vertebrae, but varied from 34 to 36, where the specimens from the rivers Gin, Kalu and Menik had 36 vertebrae. Specimens from the Nilwala River and the Walawe River mostly had 34 vertebrae, while those from the Kirindi Oya commonly had 35. The last three caudal vertebrae form the caudal skeleton (Figure 6) supporting the caudal fin with 18 principal rays (asymmetrical with 10 and 8 in upper and lower lobes, respectively). The last caudal vertebra is commonly interpreted as a compound

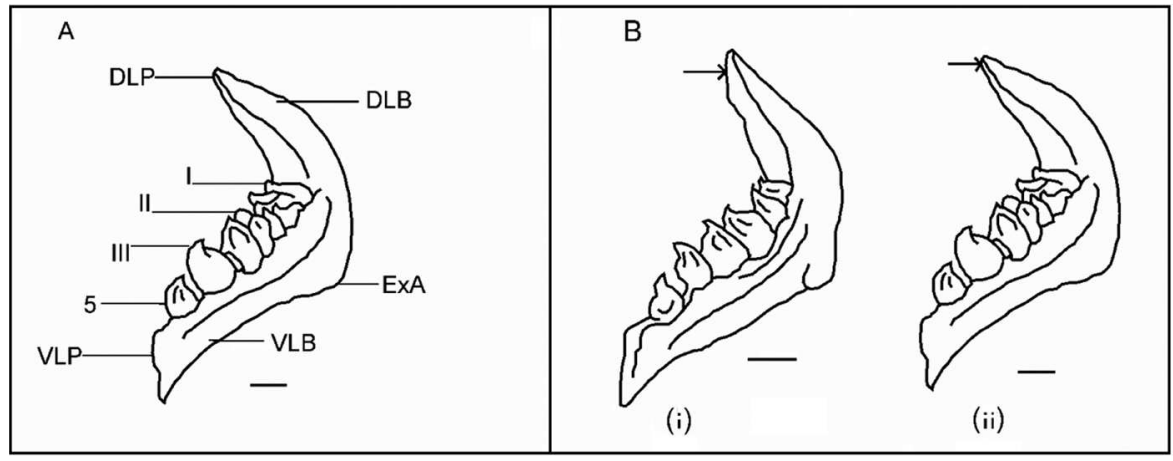

Figure 5: (A) Fifth ceretobranchial of $P$. sarana, $68.3 \mathrm{~mm}$ SL.

(DLB- dorsal limb; DLP- dorsal lip; ExA- external angle; VLB- ventral limb; VLP- ventral lip;

I- First tooth row; II- Second tooth row; III- Main row; 5- Fifth tooth in the main row).

(B). Variation in the shape of the dorsal lip of pharyngeal bones of P. sarana: (i) truncated, in Walawe River and Menik River; (ii) pointed, in other five locations (scale bar $=1 \mathrm{~mm}$ ). 


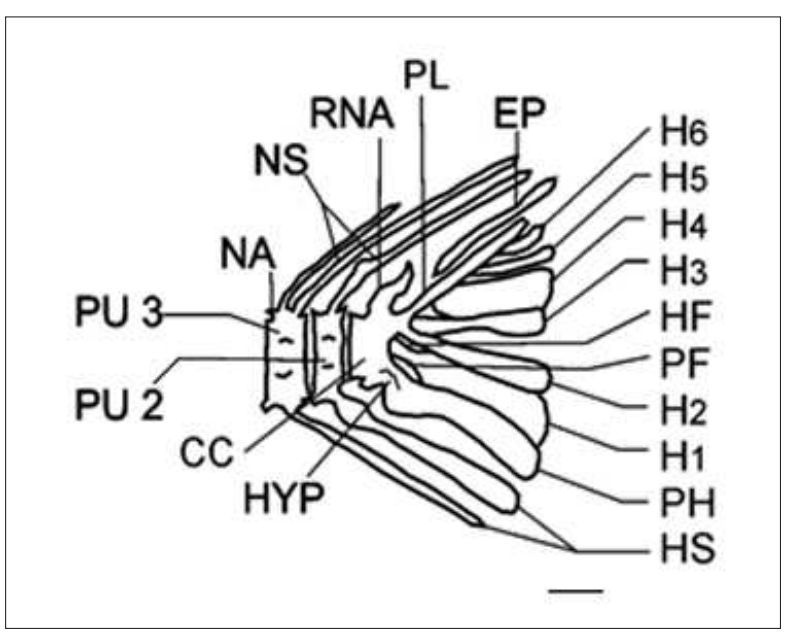

Figure 6: Caudal skeleton and preural region of $P$. sarana, $68.3 \mathrm{~mm}$ SL.

(EP-epural; HF-hypural foramen; HS-haemal spines; H (1-6)- six hypurals; HYP-hypurapophysis; NA-neural arch; NS-neural spines; PF-parhypural foramen; PH-parhypural; PU-preural centrum; CC-compound centrum; RNA-rudimentary neural arch; PL-pleurostyle (scale bar $=1 \mathrm{~mm})$.
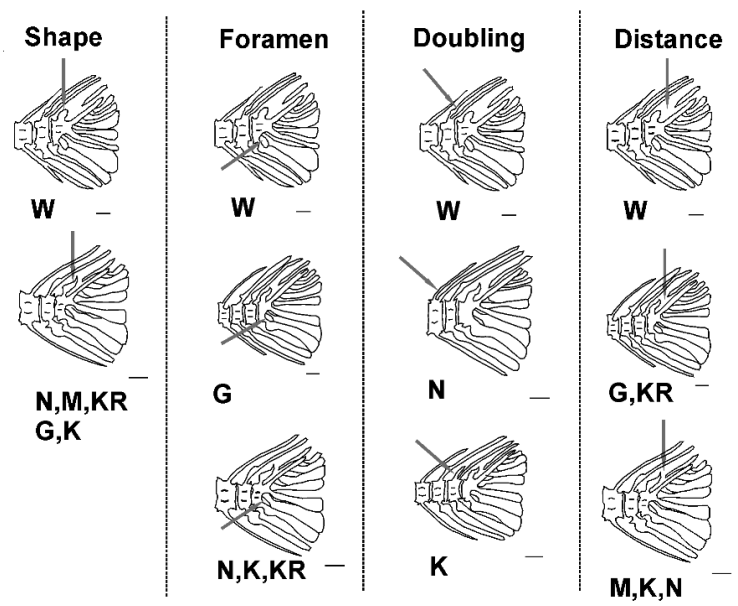

Figure 7: Caudal skeleton of $P$. sarana from six locations showing the variation in various elements $(\mathrm{W}$ - Walawe River; $\mathrm{G}$ Gin River; N - Nilwala river; KR - Kalu River; M - Menik River; $\mathrm{K}-$ Kirindi Oya) (scale bar $=1 \mathrm{~mm}$ ).

centrum formed by an assumed fusion of the first preural centrum with one or more ural centra (PU1 + U1), and three other elements fused with it, i.e. parhypural in the lower lobe, and pleurostyle and rudimentary neural arch in the upper lobe. The parhypural bears a hypurapophysis at the base, which is a tiny and bony process. Other caudal skeleton elements include six hypurals (four and two in the upper and lower lobes respectively), and a detached tiny bone called epural located antero-dorsal to the pleurostyle. In some specimens, hypurals are abutting to one another but not fused. In addition to the hypural foramen (HF) between proximal regions of the first and second hypurals, the proximal regions between the parhypural and the first hypural creates the parhypural foramen (PF). The size and the shape of PF seem to vary with the presence or absence of an invagination along the lateral margin of the proximal end of parhypural. One uroneural remains as a thin bone slip along the side of the pleurostyle, and the distal end of it can be seen in all specimens (not shown in Figure 6). The rudimentary neural arch on the dorsal facet of the compound centrum is commonly narrow, elongated and curved dorsoanteriorly near its tip. The distance between the distal end of the rudimentary neural arch and the proximal end of the epural (epural distance) seems to vary. Each of the two anterior vertebrae of the caudal element, i.e. preural centrum 2 and 3 , give rise to a dorsal neural spine and a ventral haemal spine.

Osteological preparations from six locations revealed consistent variation in various components of the caudal element as described herein (Figure 7). The shape, length and the stoutness of the rudimentary neural arch in fish from the Walawe River (W) apparently differ from the common pattern, where it is distinctively shorter and stouter than those in other rivers. The size of the parhypural foramen is also a distinctive feature where the specimens from the Walawe River (W) and the Gin River (G) showed relatively larger parhypural foramen than in other specimens. No intra-specific variation was detected in the shape or the position of the hypurapophysis of P. sarana. The epural distance considerably varies among locations where the largest gap is found in fish from the Walawe River, while it is smaller and varies slightly in fish from other locations. In contrast to the common pattern, double neural spines on preural centrum 2 (PU2) is seen in five specimens from the Walawe River (W) and in three (out of 6) specimens from the Kirindi Oya. However, the length of the doubled neural spines on PU2 showed variation between these two locations, where the spines are of similar length in fish from the Walawe River but contrastingly of different length (one is very short) in fish from the Kirindi Oya. Doubling of the neural spine of the preural centrum 3 is seen in four specimens (out of 6) from the Nilwala River (N).

\section{DISCUSSION}

The present study revealed certain differences in osteology among the six geographic populations of $P$. sarana in Sri Lanka. There is no variation in the bones forming the skull roof, but the bone arrangement seems to 
be a character for population differentiation. The median inter-frontal suture showed discernible variation, which categorized the six studied populations into one of two broad patterns, having leftward or rightward curvature. However, the examination of more specimens is required to assess whether that feature can be considered as a population specific phenotypic trait.

The pharyngeal bones of adult cyprinoids represent the fifth (V) ceratobranchials (Eastman, 1971). The shape of the pharyngeal bones has a functional role in muscle attachment and thus facilitating mastication of food (Eastman, 1971). Pharyngeal bones and teeth are important in identification of some fish species (Eastman, 1977) when supplemented with other taxonomically useful phenotypic characters. Eastman (1977) reviewed the use of bones and teeth of the pharyngeal apparatus of 22 species of catostomid fishes (family Catostomidae), and showed that the differences in pharyngeal bones may exist even if the species share similarities in diets. The shape of the dorsal tip is a diagnostically variable character in many cyprinoids focused in Eastman (1971). Differences in the shape of the pharyngeal bone of some populations of $P$. sarana may hence represent a taxonomically informative character. According to Shantakumar \& Vishwanath (2006), the dorsal limb in Indian $P$. sarana has a blunt tip. Apparently a similar dorsal limb shape was found in fish from all Sri Lankan locations, except the Walawe River and the Menik River. This raises a question as to whether the latter populations in Sri Lanka are unique, but requires more taxonomical information from both Indian and other Sri Lankan populations. Similar to that in Indian $P$. sarana (Shantakumar and Vishwanath, 2006), and Cyprinus carpio (Eastman, 1971), three rows of pharyngeal teeth occur on each ceratobranchial of $P$. sarana studied. The number of teeth on the pharyngeal bone may be variable as they may be replaced through the life of individuals, thus it is likely to show considerable interspecific variation (Eastman, 1977) apparently connected to trophic adaptations. However, the present study did not reveal any variation in the arrangement of teeth of P. sarana specimens in Sri Lanka.

The caudal skeleton is an important system for interpreting systematic and phylogenetic relationships of actinopterygian fishes (Gosline, 1961; Nybelin, 1972). It may also provide evidence for intra-specific variation in fishes (Eastman, 1980). Caudal fins of cyprinids in general, and of $P$. sarana fishes typically have six hypurals including four in the upper lobe (Buhan, 1972; Shantakumar \& Vishwanath, 2006). P. sarana specimens examined in the present study followed the same pattern. All specimens of $P$. sarana bear a parhypural foramen that may have a functional significance linked to caudal fin movements, similar to the function described for the hypural foramen (the space between the first and second hypurals) in fishes (Kampmeier, 1969). These inter-bone spaces are known to be involved in facilitating the lymph communication (Kampmeier, 1969). Variation in the size of the parhypural foramen, which is not related to fish size was seen where the specimens from the rivers Walawe and Gin bear relatively large parhypural foramen. The presence and structure of the hypurapophysis seem to have some functional significance linked to fast swimming capability as it has been linked to the caudal musculature (Eastman, 1980), particularly as an attachment site for the hypochordal longitudinal muscle (Nursall, 1963). The absence of variation in hypurapophysis of $P$. sarana may indicate its significance in all fish, as this may be a required characteristic of any fast swimmer. However, the caudal musculature of cyprinids has not been studied well (Eastman, 1980), and therefore, making any peculiar functional interpretations is difficult (Gosline, 1961). Nevertheless, according to Nursall (1963), there is no apparent change in the degree of development of the muscle with or without hypurapophysis. Uroneurals are modified ural neural arches (Arratia \& Schultze, 1992; Sanger \& McCune, 2002), and the presence of one thin uroneural along the side of the pleurostyle was a homogenous feature in all studied specimens with no intra-specific variation. First of the paired uroneurals is usually not seen as it has fused to the compound centrum, but the second one usually remains as seen in Danio species as a thin slip of bone along the side of the pleurostyle (Sanger \& McCune, 2002). They probably provide functions in protecting the terminal part of the spinal cord, as well as in ensuring that the tail functions hormocercally (Patterson, 1968).

The axial skeleton of $P$. sarana commonly consists of 36 vertebrae (Shanthakumar \& Vishwanath, 2006), and the variation in vertebral number seems to be linked to the doubling of the neural spines in the preural caudal vertebrae. For instance, specimens from the rivers Nilwala, Walawe and Kirindi, which had less than 36 vertebrae, all showed doubling of the neural spines on preural centra. It is generally believed that the doubling process is a result of vertebral fusion or more correctly, non-separation during development (Kändler, 1932). The number of vertebrae in fishes is fixed early in development, usually by the time of hatching (Gwyne, 1940; Garside, 1966), and believed to be influenced by physical, chemical and biological conditions of the water where eggs and larvae are laid and develop (Arratia, 1992). Vertebral fusion is known to be a common feature in other cyprinids as well (Eastman, 1980). The observed results are in agreement with the above interpretation, 
and indicate that the vertebral number seems to be a powerful adjunct in studies of intra-specific variation in P. sarana fish. Similar complex vertebrae have been encountered in the preural region of variety of fishes (Kändler, 1932; Barrington, 1937; Ford, 1937; Buhan, 1972; Patterson and Rosen, 1977). The preural vertebrae and caudal skeleton comprise a significant component of the morphological evidences presented in papers on fish inter-relationships (Patterson, 1968; Greenwood \& Rosen, 1971; Patterson \& Rosen, 1977; Arratia, 1997, 1999), thus the knowledge of intra-specific variation in the preural vertebrae is greatly important in fish anatomy and taxonomy.

The environment plays an important role in establishing phenotypes (Arratia \& Schultze, 1992). It has been demonstrated that the degree of constancy is often affected and characters may even vary considerably when a species comes under the influence of different environmental conditions (Tatarko, 1968). Most of the ossified structures are subjected to broad environmentally induced variation (Taning, 1952; Tatarko, 1968; Fowler, 1970) and temperature in particular is known to affect the developmental rate of ossified meristic characters, coupled to slowing or accelerating growth and differentiation (Eastman, 1980). However, in this study, temperature variations between locations are insignificant and therefore temperature would not be a strong factor that creates differences in osteological features in studied specimens. Morphological (and /or osteological) structures and their development are strongly correlated with functional requirements (Weisel, 1960; Strauss, 1990; Mabee, 2000; Maglia et al., 2001). For instance, in Barbus barbus, bony elements of the opercular region and the cranial bones involved in feeding ossify earlier than other bones (Vandewalle et al., 1992), hence, it is assumed that functional needs lead to the developmental sequences where bones implicated in early functional needs probably respond by earlier ossification.

The taxonomic significance of the variation observed in the present study has to be assessed in relation to the available taxonomic information on the species. The species described by Hamilton in 1822 from the Ganges was named as Cyprinus sarana, and later it was synonymized with Puntius sarana. However, its first description from Sri Lanka appeared as Puntius pinnauratus Day 1878 (Day 1865). Deraniyagala (1930) synonymized it with $P$. chrysopoma, while a related species with superficial appearance to it was later named P. timbiri (Deraniyagala, 1963). The identification of this species in Sri Lanka appears to have certain ambiguities, because of these synonyms and the lack of information on whether there is only a single species of
P. sarana-like fish (Pethiyagoda, 1991). The taxonomic complexity of this species has further been indicated by Talwar \& Jhingran (1991) reporting intra-specific variants that have been designated as four sub species, namely $P$. sarana orphoides, $P$. sarana subnasutus and $P$. sarana sarana from India, and P. sarana spilurus from Sri Lanka (Ceylon; type locality unknown). In the absence of systematic studies, there is an apparent taxonomic uncertainty of the Sri Lankan P. sarana, while all fish having gross external similarities to Deraniyagala (1952) description are currently named Puntius sarana. Until an extensive taxonomic study is undertaken on the species by examining all the relevant type specimens, Pethiyagoda (1991) has suggested retaining the name Puntius sarana for all related varieties that have close superficial resemblance.

According to Shantakumar \& Vishwanath (2006), there are specific osteological characters, which belong to the P. sarana group in Manipur, India. However, the same study has not revealed which sub-species they have focused on. Therefore, a useful comparison between the Sri Lankan specimens and those from other subspecies originally described from India using many osteological features was not possible. Such comparisons may contribute to the taxonomic clarification of $P$. sarana fishes in the region. Observed osteological variations provide good evidences for intra-specific heterogeneity among $P$. sarana populations, where the Walawe River population of $P$. sarana can be differentiated from other studied populations based on the shape of the rudimentary neural arch, the size of the parhypural foramen, the epural distance and the shape of the dorsal lip of fifth ceretobranchials. Accordingly, the results of the present study reveal a convincing phenotypic heterogeneity of the species among populations in rivers in Sri Lanka. Examination of more specimens representing other geographic samples from its distribution range will contribute to a wider taxonomic perception of this species.

\section{Acknowledgement}

Assistance in fieldwork by D. A. M. Dilrukshana, C. H. Priyantha, and P. H. Dinesh Dilhan, funding by National Research Council (grant NRC 05-60) and help from Dr Rohan Pethiyagoda and the research crew previously at WHT biodiversity center, Agarapathana are acknowledged. The comments of two anonymous referees on the initial manuscript are appreciated.

\section{References}

1. Arratia G. (1983). The caudal skeleton of ostariophysan 
fishes (Teleostei): intraspecific variation in Trichomycteridae (Siluriformes). Journal of Morphology 177(2): 213-229.

2. Arratia G. (1997). Basal teleosts and teleostean phylogeny. Paleo Ichthyologica 7: 5-168.

3. Arratia G. (1999). The monophyly of Teleostei and stemgroup teleosts. In: Mesozoic Fishes 2: Systematics and Fossil Record (eds. G. Arratia \& H.P. Schultze), pp. 265334. Dr Friedrich Pfeil, Munich, Germany.

4. Arratia G. \& Schultze H.P. (1992). Reevaluation of the caudal skeleton of certain actinopterygian fishes III. Salmonidae. homologization of caudal skeletal structures. Journal of Morphology 214(2): 187-249.

5. Barrington E.J.W. (1937). The structure and development of the tail in the plaice (Pleuronectes platessa) and the cod (Gadus morhua). Quarterly Journal of Microscopical Science 79: 447-469.

6. Buhan P.J. (1972). The comparative osteology of the caudal skeleton of some North American minnows (Cyprinidae). American Midland Naturalist 88(2): 484-490.

7. Day F. (1865). The Fishes of Malabar, p. 209. Bernard Quaritch, London, UK.

8. Deraniyagala P.E.P. (1930). The Eventognathi of Ceylon. Spolia Zeylanica 16(1): 1-41.

9. Deraniyagala P.E.P. (1952). A Colored Atlas of Some Vertebrates from Ceylon: Fishes, volume 1, p. 149. National Museums Publication, Ceylon Government Press, Colombo.

10. Deraniyagala P.E.P. (1963). A new cyprinid Puntius timbiri from Ceylon. Spolia Zeylanica 30: 63-65.

11. Dunn J.R. (1983). The utility of developmental osteology in taxonomic and systematic studies of teleost larvae: a review. Technical Report NMFS Circular No. 450. pp. 1-19. National Oceanic and Atmospheric Administration, Washington DC, USA.

12. Dunn J.R. (1984). Developmental osteology. ontogeny and systematics of fishes. Special Publication Number 1, American Society of Ichthyologists and Herpetologists (eds. H.G. Moser, W.J. Richards, D.M. Cohen, M.P. Fahay, A.W. Kendall \& S.L. Richardson), pp. 48-50. Allen Press Inc., Lawrence, Kansas, USA.

13. Eastman J.T. (1971). The pharyngeal bone musculature of the carp, Cyprinus carpio. Journal of Morphology 134(2): 131-140.

14. Eastman J.T. (1977). The pharyngeal bones and teeth of catostomid fishes. American Midland Naturalist 97(1): 68-88.

15. Eastman J.T. (1980). The caudal skeletons of catostomid fishes. American Midland Naturalist 103(1): 133-148.

16. Ford E. (1937). Vertebral variation in teleostean fishes. Journal of the Marine Biological Association of United Kingdom 22(1):1-57.

17. Fowler J.A. (1970). Control of vertebral number in teleosts- an embryological problem. Quarterly Review of Biology 45(2): 148-167.

18. Garside E.T. (1966). Developmental rate and vertebral number in Salmonids. Journal of the Fisheries Research Board of Canada 23(10): 1537-1551.

19. Gosline W.A.(1961). Some osteological features of modern lower teleostean fishes. Smithsonian Miscellaneous Collections 142(3): 1-42.

20. Greenwood P.H. \& Rosen D.E. (1971). Notes on the structure and relationships of the alepocephaloid fishes. American Museum Novitates 2473: 1-41.

21. Gwyne A.M. (1940). The development of the vertebral column of the Pacific herring (Clupea pallasii). Journal of the Fisheries Research Board of Canada 5:11-22.

22. Hilton E. \& Bemis W.E. (1999). Sketelal variation in short nose sturgeon (Acipencer brevirostrum) from the Connecticut River: implications for comparative osteological studies of fossils and living fishes. In: Mesozoic Fishes: Systematics and Fossil Record, volume 2 (eds. G. Arratia \& H.P. Schultze), pp. 69-94. Dr Friedrich Pfeil, Munich, Germany.

23. Ishihara H. (1987). Revision of the Western North Pacific species of the genus Raja. Japanese Journal of Ichthyology 34(3): 241-285.

24. Jayaram K.C. (1991). Revision of the genus Puntius Hamilton from the Indian region. Records of the Zoological Survey of India, Occasional Papers 135: 1-178.

25. Jayaram K.C. (1999). The Freshwater Fishes of the Indian Region, p.114. Narendra Publishing House, Delhi, India.

26. Kampmeier O.E. (1969). Evolution and Comparative Morphology of the Lymphatic System (ed. C. Charles Thomas) pp. 620. Charles C. Thomas Publishers, Springfield, Illinois, USA.

27. Kortmulder K., Padmanabhan K.G. \& Silva S.S. (1990). Patterns of distribution and endemism in some cyprinid fishes as determined by the geomorphology of SouthWest Sri Lanka and South Kerala (India). Ichthyological Exploration of Freshwaters 1(2): 97-112.

28. Kändler R. (1932). Unsicherheiten bei Bestmmung der Wirbelzahl infolge 'Verwachsungser scheinungen'. Journal du Conseil International pour l'Exploration de la Mer 7:373-385.

29. Kändler R. (1944). Untersuchungen über den Ostseedorsch während der Forschungsfahrten mit dem R.F.D. 'Poseidon' in den Jahren 1925-1938. Berichte der Deutschen Wissenschaftlichen Kommission Meeresforschung 11(2):137-245.

30. Mabee P.M. (2000). The usefulness of ontogeny in interpreting morphological characters. In: Phylogenetic Analysis of Morphological Data (ed. J. Wiens), pp. 84-114. Smithsonian Institution Press, Washington DC, USA.

31. Maglia A.M., Punener L.A. \& Trueb L.A. (2001). Comparative development of anurans using phylogeny to understand ontogeny. American Zoologist 41(3): 538551.

32. Munro I.S.R. (1955). The Marine and Freshwater Fishes of Ceylon, pp. 351. Department of External Affairs, Canberra, Australia.

33. Nursall J.R. (1963). The hypurapophysis, an important element of the caudal skeleton. Copeia 2: 458-459.

34. Nybelin O. (1973). Comments on the caudal skeleton of actinopterygians. In: Interrelationships of Fishes (eds. P.H. Greenwood, R.S. Miles \& C. Patterson), pp. 369-372. Academic Press, London, UK.

35. Patterson C. (1968). The caudal skeleton in lower Liassic 
pholidophorid fishes. Bulletin of the British Museum of Natural History (Geology) 16(5): 203-239.

36. Patterson C. \& Rosen D.E. (1977). Review of Ichthyodectiform and other Mesozoic teleost fishes and the theory and practice of classifying fossils. Bulletin of the American Museum of Natural History 158(2): 81-172.

37. Pethiyagoda R. (1991). Freshwater Fishes of Sri Lanka, pp.113.Wild life Heritage Trust of Sri Lanka, Colombo 8.

38. Sanger T.A. \& McCune R.A. (2002). Comparative osteology of the Danio (Cyprinidae: ostariophysi) axial skeleton with comments on Danio relationships based on molecules and morphology. Zoological Journal of the Linnaean Society 135: 529-546.

39. Schultze H-P. \& Arratia G. (1988). Reevaluation of the caudal skeleton of certain actinopterygian fishes II. Hiodon, Elops and Albula. Journal of Morphology 195(3): 257-303.

40. Shantakumar M. \& Vishwanath W. (2006). Inter relationships of Puntius Hamilton-Buchanan (Cyprinidae: Cyprininae) found in Manipur, India. Zoos' Print Journal 21(6): 2279-2283.

41. Strauss R.E. (1990). Heterochronic variation in the developmental timing of cranial ossifications in poeciliid fishes (Cyprinodontiformes). Evolution 44(6): 1558-1567.

42. Talwar P.K. \& Jhingran A.G. (1991). Inland Fishes of India and Adjacent Countries, volume 1, p. 258. Oxford and IBH Publishing Co., New Delhi, India.

43. Täning A.V. (1952). Experimental study of meristic characters in fishes. Biological Reviews of the Cambridge Philosophical Society 27:169-193.

44. Tatarko K.I. (1968). Influence of temperature on the meristic characters of fishes. Problems of Ichthyology 27: 425-439.

45. Tayler W.R. \& Van-Dyke G.C. (1985). Revised procedures for staining and clearing small fishes and other vertebrates for bone and cartilage study. Cybium 9(2): 107-119.

46. Vandewalle P., Focant B., Huriaux F. \& Chardon M. (1992). Early development of the cephalic skeleton of Barbus barbus (Teleostei, Cyprinidae). Journal of Fish Biology 41(1): 43-62.

47. Weisel G.F. (1960). The osteocranium of the Catostomid fish, Catostomus macrocheilus. A study in adaptation and natural relationship. Journal of Morphology 106(1): 109-130. 